\title{
DOUBLE-FLOWER OF P. PRIMULIFLORA
}

MITSUAKI BAN

This reports details of P. primuliflora "Rose" (double-flower) which I posted in the "Trade" page of the previous issue of Journal of IPS (J.IPS).

I found this variety among $P$. primuliflora plants blooming in my non-heated cold frame in May 1995. I consider this as a spontaneous mutant seedling. As I keep P. primuliflora plants in a nonheated cold frame throughout the year, the flowering season is mid-April, almost the same as the natural flowering season. Also many bees were flying around in the cold frame in the season. Therefore, insect pollinations seem to have happened and about $30 \%$ of the flowers produced seeds. I didn't intentionally collect the seeds, because this plant can be easily propagated asexually. However, unexpected seedlings came out from some pots and the double-flowered variety was one of them.

Cultivation of the variety is very easy, not different from the cultivation method for common P. primuliflora. Judging from the fact that all of about 60 plants had double flowers this year, this double-flower character seems to be stable. The number of petals varies depending on the plants' conditions; healthy plants have more than 5-layer flowers. The double-flower petals seem to derive from pistil, as only stamens remain when all petals are removed. I would like to give a name to this variety P. primuliflora "Rose," because the flower's appearance is reminiscent of a rose flower.

Butterworts of Section Isoloba are very often kept in heated cold frames in winter and such plants' flowering season shifts to February. Because of absence of polliniferous insects in the season, they hardly produce seeds unless pollinated artificially. As $P$. primuliflora propagates asexually through budbreak from leaf tips, its seeds are usually not purposely collected by the growers. Use of heated cold frames could be one of the reasons why P. planifolia, P. caerulea and so on have not become widely prevalent.

Actually, both my short report and my trade page posting were supposed to appear in the previous issue of J.IPS. However, Mr. Satoru Ishizaka, living in Seto City, also submitted a picture of his double-flowered P. primuliflora for trade posting and IPS, Japan asked me to rewrite my article after checking Ishizaka's pictures. While I was communicating with Mr. Ishizaka and checking his picture, I missed the deadline to submit the rewritten article. Thus only my trade page posting appeared in the No. 3 issue. When I asked Mr. Ishizaka about his doubleflowered P. primuliflora, he explained that he ob-

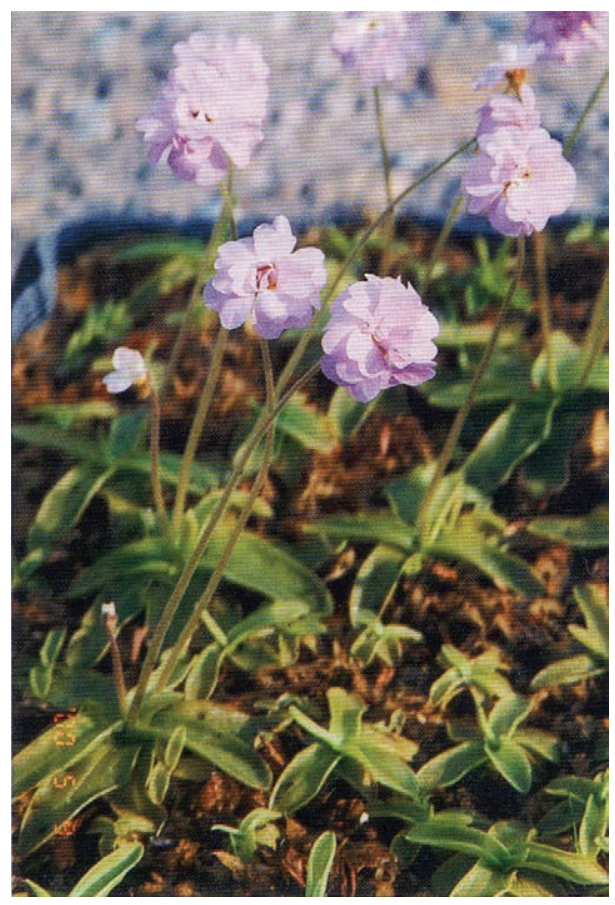

Pinguicula primuliflora 'Rose'. Scanned image from the October 2000 J.IPS 51(4) provided by Naoki Tanabe, JCPS Chairperson. 
tained his P. primuliflora from Mr. Masahiro Kondo and had been maintaining it for many years. His P. primuliflora plants were once about to die down but recovered later. He found a double-flowered plant among the recovered plants. As I knew that he also obtained my double-flowered lineage from an ex-IPS, Japan member, living in Agui Town, to whom I shared my double-flowered plant in 1995, I thought both lineages might be identical. However, Mr. Ishizaka told me that his double-flowered lineage was different from my lineage. Petals of his double-flowered plants are 2 layers or so, not more than 3 layers. Therefore, I name my lineage P. primuliflora "Rose" (Type Ban) to differentiate from Ishizaka's lineage. I have obtained Mr. Ishizaka's consent for this nomenclature.
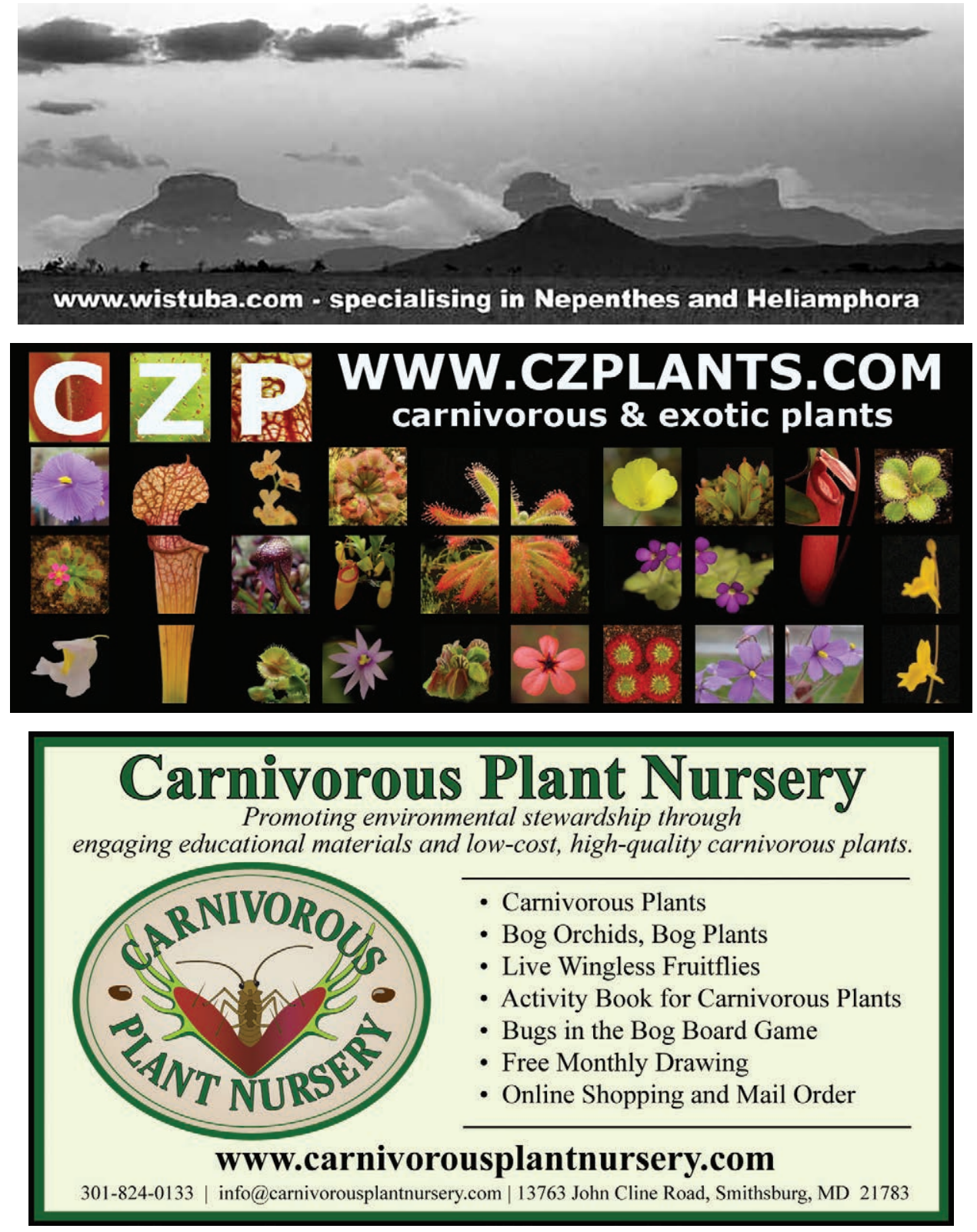